\title{
Biblioteca Pública de Nova Goa: alguns aspectos da sua agenda intelectual ${ }^{1}$
}

\author{
SANDRa Ataíde Lobo \\ Centro de História da Cultura - Universidade Nova de Lisboa
}

RESUMO: A BIBLIOTECA CENTRAL DE PANGIM TEM UMA LONGA HISTÓRIA, SENDO CONSIDERADA A PRIMEIRA BIBLIOTECA PÚBLICA DA ÍNDIA. NESTE ARTIGO ABORDO ALGUNS ASPECTOS DA SUA AGENDA INTELECTUAL NA VIRAGEM DO SÉCULO IX PARA O SÉCULO XX, QUE REVELAM COMO AS POLÍTICAS PÚBLICAS SOBRE A LEITURA SE LIGAM À CONSTRUÇÃO IDENTITÁRIA, E COMO NO CONTEXTO COLONIAL PODEM SER USADAS PELOS AGENTES NATIVOS PARA PROMOVER UMA CONSCIÊNCIA IDENTITÁRIA LOCAL.

ABSTRACT: THE CENTRAL LIBRARY OF PANGIM HAS A LONG HISTORY, AND IS CONSIDERED TO BE THE FIRST PUBLIC LIBRARY IN INDIA. IN THIS ARTICLE I DEAL WITH CERTAIN ASPECTS OF ITS INTELLECTUAL AGENDA BETWEEN THE END OF THE $19^{\text {TH }}$ AND THE BEGINNING OF THE 20 TH CENTURY, WHICH REVEAL HOW LOCAL GOVERNMENT POLICIES CONCERNING READING CONTRIBUTE TO IDENTITY CONSTRUCTION, AND HOW IN A COLONIAL CONTEXT THEY MAY BE USED BY NATIVE AGENTS TO RAISE CONSCIOUSNESS OF A LOCAL IDENTITY.

PALAVRAS-CHAVES: BIBLIOTECAS PÚBLICAS; POLITICAS PARA O LIVRO E LEITURA; ELITE INTELECTUAL GOESA; ORIENTALISMO EM GOA; IDENTIDADE CATÓLICA GOESA; HISTÓRIA CULTURAL DE GOA (SÉC. 19-20)

KEYWORDS: PUBLIC LIBRARIES; BOOK AND READING POLITICS; GOAN INTELLECTUAL ELITE;ORIENTALISM IN GOA; GOAN CATHOLIC IDENTITY; CULTURAL HISTORY OF GOA (19 $9^{\text {TH }}-20^{\text {TH }}$ CENTURY)

1. Uma versão inglesa deste texto, algo mais abreviada, foi publicada com o título "Some aspects of the Intellectual Agenda of Central Library's History" in FERNANDES, Carlos et al. (eds)., Public libraries of the 21st Century. Pangim:, Directorate of Arts \& Culture, Government of Goa, 2010. 
Biblioteca Central de Pangim tem uma longa história, sendo considerada a primeira biblioteca pública da Índia. Para o investigador que queira estudar a história contemporânea goesa, a Central Library apresenta-se como instituição de frequência incontornável mercê do seu rico espólio, não só pelas numerosas monografias que não se encontram em outras bibliotecas, mas, sobretudo, pela rica colecção de jornais e revistas, sem os quais não é possível entrar na vida das ideias e na dinâmica das sociedades contemporâneas. Neste artigo abordarei alguns aspectos da sua agenda intelectual entre finais do século IX e primeiros anos do século XX, relacionando-a com a reflexão identitária goesa coeva.

\section{Bibliotecas em mudança}

Aquando da criação em 1832 da Biblioteca Pública de Nova Goa, o conceito de biblioteca pública estava longe de ter estabilizado na Europa. Apesar de desde o século XVI se encontrarem bibliotecas detidas por instituições públicas, a ideia de uma política governamental para o desenvolvimento de Bibliotecas Públicas decorre das concepções iluministas sobre a responsabilidade e interesse do Estado instruir e educar os cidadãos, bem como da consolidação do Estado-Nação oitocentista.

A convicção de que a formação de bons cidadãos estava intimimamente ligada a uma bem orientada aquisição de conhecimentos e formação moral/ ética, na qual os livros tinham um papel decisivo a desempenhar, suporta o crescimento dum discurso público em prol da disseminação de bibliotecas públicas. Através destas instituições os Estados Modernos providenciariam aos seus cidadãos os instrumentos para apoiar ou desenvolver as aquisições da educação formal. No entanto, a ideia demorou a enraizar-se, pelo que o moderno conceito de biblioteca pública como biblioteca generalista, suportada pelos impostos e aberta a todos os cidadãos, teria de esperar na maioria dos países europeus pelos finais do século IX e mesmo as primeiras décadas do século XX para se implantar. ${ }^{2}$

Em muitos aspectos, o desenvolvimento da Biblioteca Pública de Nova Goa acompanha as tendências das suas congêneres europeias. O simples fato

2. Sobre esse tópico cf. HARRIS, 1995, p. 148-149. 
da criação duma biblioteca pública em território colonial numa data tão remota é em si notável, e só é explicável pelo estatuto particular de Goa enquanto capital do Estado português da Índia.

É geralmente conhecido que essa instituição centenária, a mais antiga biblioteca pública existente na Índia, tem o seu berço na iniciativa do vice-rei miguelista D. Manuel de Portugal e Castro, ao ordenar em 1832 a criação duma Pública Livraria anexa à Academia Militar. ${ }^{3}$ A intenção do vice-rei seria a de servir os estudantes da Academia - sobretudo jovens metropolitanos ou descendentes - , visando a "adiantar a pública educação da mocidade, principalmente no que respeita à instrução militar em comum benefício do Estado e utilidade do Real serviço". ${ }^{4}$

Em 1836, o Governo Provisional do Estado da Índia rebatizaria-a de Biblioteca Pública e ordenaria a integração na instituição dos livros e manuscritos oriundos dos Conventos de Velha Goa, ${ }^{5}$ entretanto extintos. Com esse passo a biblioteca de Nova Goa adquiria uma função de preservação. Em Março de 1841, uma nova reforma sublinharia essa vocação ao determinar a separação da biblioteca da Academia Militar e da Biblioteca Pública, guardando aquela somente as obras que versavam temáticas militares e matemáticas. Os livros e manuscritos dos antigos conventos deveriam constituir a coleção nuclear da Biblioteca Pública.

Em 1870, o decreto de 30 de abril inauguraria uma nova fase na renomeada Biblioteca Pública de Nova Goa, dotando-a, pela primeira vez, dum fundo anual para a aquisição de livros. O orçamento, limitado embora, permitia o desenvolvimento de uma nova política para o catálogo, até aí confinado ao legado dos conventos e à expansão por via das publicações oficiais e donativos privados $^{6}$. A instituição podia daí em diante definir um perfil desejável para

3. Até ao século 19 a palavra "livraria" designava uma livraria, um depósito de livros ou uma biblioteca. Só a partir dessa altura, é que lentamente começaram a serem separados os conceitos de livraria e biblioteca.

4. Portaria de 15 de Setembro de 1832 (FERREIRA, 1906, p. 3).

5. Em Lisboa a mesma tarefa seria conferida à Biblioteca Nacional de Lisboa em 1841.

6. A Livraria do cônego Caetano João Peres, na altura considerada uma das melhores de Goa, foi o primeiro fornecedor da biblioteca (GRACIAS, 1892, p. 3; FERREIRA, 1906, p. 12). Mais tarde, Ismael Gracias, num artigo sobre a história do Instituto Vasco da Gama, conta que a biblioteca do Instituto tivera por núcleo precisamente essa biblioteca, cedida pelo sobrinho, Joaquim Gustavo Adolfo Peres, pelo tempo que o Instituto vivesse. A biblioteca do cônego Peres era constituída por 808 volumes (GRACIAS, 1909, p. 135). Possivelmente com o fim da atividade do Instituto, em 1875, a Biblioteca Pública terá aproveitado a oportunidade para adquirir as obras. 
a sua coleção, em conexão com as expectativas geradas por uma Biblioteca Pública ao serviço de uma sociedade concreta. É a partir dessa data que podemos considerar que se adequou a sua vocação a fins inerentes ao conceito de Biblioteca Pública.

Entre 1879 e 1888 a Biblioteca seria orientada por uma Comissão Diretora nomeada pelo governador do Estado da Índia 7 . A Comissão foi responsável por vários melhoramentos nas instalações e funcionamento da biblioteca, entre eles a criação de uma seção de numismática, no seguimento da proposta do numismata e arqueólogo José Maria do Carmo Nazareth. ${ }^{8}$

Em 1889, seria publicado um novo Regulamento ${ }^{9}$ visando ao desenvolvimento da biblioteca e interpretando as concepções coevas sobre bibliotecas públicas à luz da ideologia do Estado Liberal Católico português. Antes de mais, estabelecia os objetivos democratizadores da biblioteca, definindo como seu público todos os cidadãos independentemente da classe. Em segundo lugar, determinava o controle ideológico da leitura ao atribuir ao bibliotecário a decisão de limitar o acesso a impressos ou manuscritos "cuja leitura possa considerar-se nociva à mocidade estudiosa, ou ofensiva da moral pública ou do respeito devido à Igreja, ao Estado, às instituições e à autoridade constituída”. Finalmente, definia a responsabilidade do Diretor melhorar a organização da biblioteca e contribuir para a visibilidade pública da instituição, obrigando-o nomeadamente: a contatar autoridades locais e instituições estrangeiras acerca de matérias bibliográficas e literárias com vista ao enriquecimento da colecção; a organizar os catálogos da biblioteca; a apresentar um relatório anual ao governador-geral e a publicar as estatísticas de leitura no Boletim Oficial.

Genericamente, esse regulamento traduzia a vontade de dotar a Biblioteca Pública com os meios necessários para a sua actualização às visões correntes

7. A comissão era composta pelo secretário-geral, que presidia a Comissão, por Luís Carneiro de Souza e Faro e Floriano Mateus do Rosário Barreto. O último seria substituído a 10 de março de 1884 por José António Ismael Gracias. Nesse período foram sucessivamente secretários-gerais: Eduardo Augusto de Sá Nogueira Pinto de Balsemão, José Maria Teixeira Guimarães, Ignácio Rodrigues da Costa Duarte e Eugénio Eduardo Mascarenhas de Menezes. Anteriormente tinham dirigido a Biblioteca: José António de Lemos (desde 1832), António Manuel Soares da Veiga (desde 1842), e Plácido da Costa Campos (desde 1869). (FERREIRA, 1906, p. 56).

8. Carmo Nazareth (cf. GRACIAS, 1892, p. 2; COSTA, [s.d.], vol. II, p. 334-5) seria por longos anos o responsável pela seção.

9. Boletim Official, n. 34, 28 março 1889. 
sobre essas intituições, vistas como instrumentais para a expansão dos recursos intelectuais das sociedades. Esse voluntarismo energizante reflete-se ainda no esforço de dar visibilidade pública à biblioteca, nomeadamente através da publicação no Boletim Oficial ou em panfletos dos relatórios anuais dos seus diretores, das estatísticas de leitura ${ }^{10}$, das listas de novidades, de catálogos parciais, de anúncios sobre as aquisições mais relevantes.

Culminando esse processo em 1897, pelo decreto de 15 de fevereiro, a biblioteca seria elevada à categoria de Biblioteca Nacional. Apesar de o texto do decreto ser extremamente lacônico, não enunciando os propósitos dessa importante decisão, as suas implicações simbólicas e práticas devem reter a nossa atenção.

Ao tornar-se uma Biblioteca Nacional, a Biblioteca Pública de Nova Goa era equiparada à Biblioteca Nacional de Lisboa. Há que notar que, na altura, essa decisão não seria replicada em qualquer outra cidade portuguesa. Simbolicamente significava o reforço do estatuto de Goa, como cabeça do único território a ter a categoria de Estado no império português. ${ }^{11}$ A elevação acontecia no contexto do novo esforço do poder colonial pacificar o território, em armas desde a revolta dos Ranes em 1875, ao responder a algumas das reclamações goesas de desenvolvimento nos campos político, econômico, educativo e cultural.

Para as relações institucionais com outras bibliotecas esse novo estatuto era decisivo, pois não mais se apresentava como uma simples biblioteca pública local, mas antes como uma biblioteca central. Esse fato permitia o desenvolvimento de protocolos de troca bibliográfica com outras bibliotecas congê-

10.As estatístiscas de leitura constituem uma importante fonte para o estudo dos hábitos de leitura, os quais podem alterar-se em momentos singulares da vida das populações. Verificamos essa situação na biblioteca pública goesa em finais do século 19. No relatório de julho de 1895 , referente ao ano econômico de 1894-1895, o então bibliotecário J. A. Ismael Gracias dava notícia de 8.377 leitores, dos quais 3.503 teriam requisitado livros e 5.324 jornais (GRACIAS, 1895, p. 44). Em outubro desse ano, as estatísticas referentes ao $3^{\circ}$ trimestre referem 3.280 leitores de jornais, ou seja, mais de metade dos leitores dum ano inteiro (Boletim Official, n. 109, 8 de out. de 1895). Estamos convencidos de que esse número extraordinário está intimamente ligado ao aumento das tensões políticas no território, que desembocariam na revolta militar de setembro logo seguida de uma revolta de contornos político-sociais, na sequência da qual o território veria suspensas as garantias e interdita a imprensa durante cerca de dois anos, e até proibida a circulação de jornais estrangeiros.

11. Nesse sentido, confirma a posição singular do Estado da Índia na hierarquia do império, tal como a Carta Orgânica de 1869 já tinha definido. 
neres, nomeadamente com as principais bibliotecas públicas e universitárias europeias e americanas. Essa consequência representava em si um tremendo alargamento das oportunidades da Biblioteca atualizar-se ao que de pertinente era publicado, num mundo que assistia ao crescimento exponencial da produção bibliográfica. A ideia duma cooperação internacional, desenvolvida em finais do século IX, visava colmatar parcialmente uma das aspirações das bibliotecas nacionais: serem o espelho dos maiores testemunhos do desenvolvimento intelectual e criativo da civilização humana.

Acima de tudo, tornar-se uma Biblioteca Nacional significava ser dotada de um propósito patrimonial, constituindo-se como local de preservação da memória nacional. ${ }^{12}$ No contexto colonial, a leitura desse propósito representava uma questão maior. Como tal, torna-se ainda mais surpreendente o laconismo do decreto. Qual a memória a ser preservada? Por outras palavras, o que deveria ser interpretado como "Nacional” no propósito de construção patrimonial? Deveria ser compreendido que doravante a Biblioteca duplicaria a vocação da Biblioteca Nacional de Lisboa, de preservar os materiais para a reconstituição da história intelectual e cultura portuguesa? "Nacional" significando, neste caso, Português. Deveria incluir uma memória Indo-Portuguesa? Ou "Nacional" significava o reconhecimento do direito do território sublinhar um patrimônio e um percurso intelectual, diferente do português metropolitano? Ao não clarificar o propósito da decisão, o legislador evitava um problema sensível, relegando as interpretações para o futuro.

\section{As visões de dois diretores (1892-1906)}

O Regulamento de 1889 determinava que o Director-Bibliotecário era responsável pela persecussão dos novos objetivos da biblioteca. Assim sendo, o perfil do bibliotecário tornou-se central ${ }^{13} \mathrm{e}$, compreensivelmente, foi reforçada a tradição de nomear indivíduos de reconhecida craveira intelectual. A

12.Sobre esse aspecto, cf. JACOB, 1996, p. 11.

13.Esse regulamento determinava que o bibliotecário deveria ser "um funcionário público de reconhecida reputação literária" (Boletim Official, no 34, 28 março 1889). Mais tarde, pelo Regulamento de 1900 que inicia a profissionalização do cargo, é indicado que o nomeado seria "pessoa idônea de reconhecida competência, inteireza e probidade" (Boletim Official, n. 28, 10 abril 1900). 
tendência para nomear para o cargo indivíduos da intelligentsia católica nativa ${ }^{14}$ reflete o papel central dessa elite nas diferentes esferas da vida política e cultural goesa, na segunda metade do século XIX. ${ }^{15}$ Analisemos alguns dos textos de dois dos seus diretores, respeitantes à sua atividade na Biblioteca - José António Ismael Gracias e Guilherme Octaviano Ferreira.

Ismael Gracias, como era conhecido, foi o diretor da Biblioteca entre julho de $1892^{16}$ e Dezembro de $1895,{ }^{17}$ sendo seguro que a sua demissão teve motivações políticas. ${ }^{18}$ José António Ismael Gracias (1857-1919), ${ }^{19}$ brâmane cristão oriundo de Loutulim, era um ator chave dos círculos intelectuais do seu tempo. Tendo completado o Liceu (1874) e feito, com brilho, múltiplas cadeiras dispersas pelas instituições de ensino médio e superior existentes em Goa, Ismael Gracias era, sobretudo, um autodidata, sendo conhecido como um trabalhador incansável, dotado duma memória prodigiosa. Tendo abraçado a vida pública em 1876, ingressando na secretaria-geral do governo do Estado da Índia, quando estava a frequentar o curso de medicina, aos 23 anos, já era chefe de repartição. A sua entrada na vida pública coincidiu com os anos

14.Desde 1889 o cargo foi ocupado pelo advogado e político António Felix Pereira (1889); pelo advogado, professor e erudito L. M. Júlio Frederico Gonçalves (1889-1892); pelo historiador, jurisconsulto e bibliógrafo José António Ismael Gracias (1892-1895); pelo juiz e poeta metropolitano Alberto Osório de Castro, nos conturbados anos de 1895 a 1897; pelo procurador público Manuel Lopes de Quadros (1897-1900); e, finalmente, por Guilherme Octaviano Ferreira (1900-1930). Todos eles, exceto um, goeses

15.Cf. RODRIGUES (2000) e ver também a interessante tese de doutoramento de Rochelle Pinto (PINTO, 2007). O investimento, renovado ao longo do século, dessas elites numa educação média e superior foi fundamental para assegurar a sua posição social, e para conferir autoridade aos seus constantes clamores para dominar os cargos públicos e intervir no espaço público goês.

16.Decreto n. 379 de 27 de julho (Boletim Official, n. 83, 28 de julho de 1892).

17. Boletim Official, n. 134, 5 de dezembro de 1895.

18. Era pública a ligação política de Gracias ao partido "Ultramarino" liderado pela família Bruto da Costa. Uma corrente "europeísta" de funcionários e militares metropolitanos - suportada pelos ideários racistas e colonialiastas finisseculares e como tal lidando mal com o ascendente local e notoriedade nacional das elites goesas - queria fazer crer ter esta família instigado uma insurreição de caráter nativista. Para animar os ânimos tinham sido fundamentais os violentos artigos contra o funcionalismo europeu publicados pelo jornal Brado indiano, dirigido pelo padre Álvares, membro da família. Sabia-se que o jornal era anonimamente colaborado por destacadas figuras do partido ultramarino, apontando-se entre elas a figura de Ismael Gracias. Sobre esse assunto a obra mais atual construída a partir dos discursos goeses é a já mencionada tese de Rochelle Pinto.

19. Para informações sobre José António Ismael Gracias cf. COSTA, [s.d.], vol. II, p. 133-144; TEIXEIRA e DIAS, 2007. 
finais da presença de Cunha Rivara em Goa, parecendo haver indícios de que o historiador português patrocinou esta jovem esperança. ${ }^{20}$

$\mathrm{Na}$ altura da sua nomeação para director da Biblioteca Pública, Ismael Gracias já tinha bem estabelecida a sua reputação intelectual, suportada por uma abundante bibliografia publicada, repartida por monografias e artigos dispersos em jornais e revistas, tendo-se dedicado particularmente às questões administrativas e à história de Goa; e por uma ativa intervenção na vida cultural e política goesa. Mais ainda, o novo direcor fora um dos autores do Regulamen$t^{21}$ de 1889, estando por isso numa posição privilegiada para interpretar o seu espírito. O seu empenho em promover a visibilidade da Biblioteca Pública reflete-se na preocupação de publicar os relatórios anuais ao governador.

O seu primeiro relatório ${ }^{22}$ foi produzido pouco depois de ter sido nomeado na sequência da resignação apresentada por Júlio Frederico Gonçalves. Tendo em conta que em 1892 a Biblioteca completava 60 anos, Ismael Gracias concentrou-se em historiar o seu percurso e dar conta do ponto de chegada, apresentando a sua visão para o futuro da instituição. Ao mesmo tempo em que apontava como um criterioso uso dos fundos tinha já permitido construir uma pequena coleção de obras seletas, o atual diretor notava, no entanto, as enormes carências e atraso bibliográfico da sua oferta. Diante desse panorama, Ismael Gracias anunciava a intenção de preencher as omissões mais notórias, privilegiando os "debates do dia", os diferentes ramos das ciências naturais, econômicas, sociais e históricas, a literatura portuguesa, e as obras versando temáticas indianas.

Mais tarde, ao relatar o seu primeiro ano de atividade, ${ }^{23}$ Ismael Gracias elucidaria e justicaria a sua política de compras. Referindo que tinha dado preferência às publicações dedicadas às matérias indianas, ${ }^{24} \mathrm{o}$ intelectual usou

20.Embora já não desempenhando as funções de secretário-geral, Cunha Rivara permaneceria em Goa até 1877, envolvido no seu trabalho de investigador, tendo publicado o Arquivo Oriental Português até 1876. Está por estabelecer a influência de Cunha Rivara na formação historiográfica de Ismael Gracias. 21.O regulamento foi preparado por uma Comissão formada pelo Tenente Coronel Luiz Carneiro de Souza e Faro, diretor do Instituto Profissional, Ismael Gracias e por Luís Manuel Júlio Frederico Gonçalves.

22.Cf. na bibliografia deste trabalho GRACIAS, 1892.

23. Rochelle Pinto (2007, p. 49-50). já chamou a nossa atenção para esse relatório (GRACIAS, 1893).

24. Antes dele, António Felix Pereira tinha doado o seu salário de bibliotecário para a aquisição de libros relacionados com a Índia (GRACIAS, 1892). 
a ocasião para criticar a polítical cultural portuguesa em solo indiano. Esse criticismo bebia no novo entusiasmo que os intelectuais goeses vinham dedicando aos estudos orientais, encarados como instrumentais para uma política colonial bem informada ${ }^{25}$ e como referenciais para a refundação duma memória local. Memória reconstituída à luz da mente europeia, que pudera impor um modelo universalizante de modernidade civilizacional, o qual ecoava nos diferentes campos literário e científico, e especificamente nas especialidades dedicadas ao escrutínio das civilizações não europeias. ${ }^{26}$

Os portugueses, Ismael Gracias acusava, "pouco conheceram e exploraram a Índia, ocupados na árdua obra de conquista e avassalamento, na meritória tarefa da conversão do gentio, actualmente reduzidos por sinistra estrela ao domínio duma parcela mínima". ${ }^{27}$ Esta atitude lusitana contrastava com o vigoroso desenvolvimento dos estudos orientais no resto da Europa, em particular na França, na Alemanha e no Reino Unido:

[Os ingleses] têm expendido e continuam a expender milhões em desfiar e perquirir o imenso mosaico de povos e raças, de religiões e línguas, como este que se estende dos Himalaias ao Comorim, e a fazer persistentes escavações arqueológicas e históricas na terra de Baratha e dos árias. (GRACIAS, 1893, p. 4)

Não duvidando da existência de uma hierarquia na credibilidade das narrativas nativas e europeias, o historiador-bibliotecário sublinhava que nesses países os acadêmicos trabalhavam na reconstrução duma memória indiana, ao imprimir "trabalhos, raros e inéditos, de antigos cronistas, navegadores e viajantes (...) importantíssimas para retificar lendas e relações indígenas”. ${ }^{28}$

25. "Na grande congerie das publicações orientais (...) tratam muitas da política e administração colonial, cujo estudo é profícuo ao funcionalismo.” (GRACIAS, 1893, p. 5).

26. "[Orientalism is] a created body of theory and practice in which, for many generations, there has been a considerable material investment. Continued investment made Orientalism, as a system of knowledge about the Orient, an accepted grid for filtering through the Orient into Western consciousness" "it is, rather than expresses, a certain will or intention to understand, in some cases to control, manipulate, even to incorporate, what is a manifestly different (or alternative and novel) world. (SAID, 2003, p. 6, 12).

27. Discordamos totalmente de Rochelle Pinto na sua afirmação de que Ismael Gracias defende nesse relatório a relação entre acumulação de conhecimento e expansão colonial (PINTO, 2007, p. 50). Não encontramos em qualquer lugar desse texto tal conexão. Diferente é o fato de Ismael Gracias apontar a responsabilidade de o colonizador conhecer e revelar os povos dominados.

28.Idem, ibidem. 
E recordava, com grande satisfação, não só as inúmeras referências, nos estudos orientais, a Goa e à governação portuguesa na Ásia, mas igualmente a inclusão de textos portugueses no itinerário de fontes para o estudo de populações não europeias, nomeadamente através das traduções promovidas pela londrina Hakluyt Society. Esse panorama justificava e revelava a indispensabilidade do investimento iniciado pela Biblioteca da "Capital do antigo Império Luso-Indiano".

No relatório do ano seguinte, Ismael Gracias continuava a justificar a utilidade de construir essa coleção, agora sublinhando como os estudos orientalistas tinham revelado a civilização indiana, consagrando-a como berço da humanidade. Na Europa, o impacto dessa "descoberta" tornava aplicável a frase horaciana Graecia capta ferum victorem cepit, tendo o Oriente, e em particular a Índia, sido eleito como campo privilegiado da actividade intelectual europeia: "[A Índia] avassalou os seus conquistadores [...] todas as inteligências, todos os filósofos e legisladores e poetas e sábios vão perscrutar-lhe as civilizações, estudar-lhe o passado que se mostra cada vez mais grandioso e deslumbrante" (GRACIAS, 1894, p. 3).

A detalhada descrição que faz sobre o panorama intelectual coevo é usada por Ismael Gracias para sublinhar, citando Émile Sénard, como o orientalismo oitocentista tinha "manifestado à Europa a Ásia", transformando-a num livro aberto, "desvelando os seus mistérios, alumiando, fazendo quase falar os seus monumentos, não descobrindo apenas um livro, ou uma série arqueológica ou uma linha de fragmentos arquitetônicos, mas uma civilização inteira, plena, vigorosa e alevantada" (GRACIAS, 1894, p. 6). Esse desvelo incluía o estudo da História da Índia e dos seus heróis, cuja grandeza era medida por comparação com os modelos europeus, ${ }^{29}$ bem como a publicação e tradução dos textos clássicos indianos, não raro apresentados como espelhos orientais dos clássicos europeus. ${ }^{30}$

29. “Asoka - o célebre rei da famosa Magadha, cognominado por seus éditos Constantino, o CarlosMagno e o S. Luís do mundo indiano, - de Akbar, o poderoso Grão-Mogol cujo reinado coincidiu e rivaliza com o de Isabel, da Inglaterra, - de Aurengzeb que no carácter, sagacidade, fausto, e até na intolerância e fanatismo religioso, pode ser comparado ao seu contemporâneo do Ocidente, Luís XIV” (GRACIAS, 1893, p. 8).

30. Ecoando comparações correntes no seu tempo, alguns anos mais tarde, o bibliotecário José Maria de Barros Valadares e o diretor da biblioteca, Octaviano Ferreira, refeririam o Mahabharata e o Ramayana como a Odisseia e a Iliada indianas (VALLADARES, 1905, p. 7; FERREIRA, 1906, p. 34-35). 
A Índia revelada pelo Orientalismo era uma Índia que se mostrava não somente ao mundo ocidental, mas às próprias elites indianas. Para os goeses, particularmente para as elites católicas pela sua secular assimilação à cultura europeia e desvinculação ideológica da cultura indiana, a iniciação ao Orientalismo acadêmico deve ter tido um profundo impacto na reflexão sobre a identidade goesa, mormente por despertar o orgulho de pertença a uma civilização milenar cujo patrimônio era reconhecido pelos próprios poderes dominantes. O entusiasmo de Ismael Gracias pelos progressos desses estudos reflecte-se nos seus sucessivos relatórios, traduzindo um estado de espírito disseminado por muitos textos goeses coevos.

A nova atitude é reflectiva num novo interesse no inquérito e análise da história $^{31}$ e realidade local, num esforço de compreender a especificidade goesa diante da Índia e de Portugal, bem como numa avaliação crítica das responsabilidades portuguesas na estruturação da condição goesa. Reflexão imbricando o problema da identidade reconhecida e da identidade desejada. Nesse campo, mostra-se igualmente inspirador o contacto com o desenvolvimento do nacionalismo cultural e político do outro lado da fronteira, sendo admirado o dinamismo dos seus líderes na promoção do Renascimento indiano. ${ }^{32}$

A política de Ismael Gracias de constituição dum núcleo dedicado às questões indianas seria desenvolvida por Octaviano Guilherme Ferreira, ${ }^{33}$ quando

31. Preocupado com a preservação da memória local, Gracias sugere logo no seu primeiro relatório a centralização na biblioteca de todos os documentos espalhados pelos arquivos públicos e privados, e noticia a criação de uma coleção museológica constituída por objetos arqueológicos e artísticos reunidos para a Exposição Agrícola de Velha Goa, em Dezembro de 1890, por ocasião de mais uma exposição do Corpo de S. Francisco Xavier. Adicionalmente, Gracias mostrava uma grande preocupação com a preservação de manuscritos interessando à história goesa, denunciando a contínua depredação dessas fontes. O diretor recordava que esse desleixo tinha uma origem metropolitana, sendo que só recentemente medidas firmes tinham sido tomadas para combater o "estado lamentável dos arquivos, os extravios e as verdadeiras barbaridades que neles se praticaram” (GRACIAS, 1892, p. 4-6).

32. "A coleção de biografias e discursos de índios eminentes (...) uma irrupção de caracteres e talentos, uma Via Láctea de patriotas, hindus e parses, a promoverem por instituições, como o congresso nacional indiano, por conferências provinciais e comícios, o progredimento do seu país natal, e a emancipação civil dos seus concidadãos" (GRACIAS, 1893, p. 6).

33 Só consegui rastrear um relatório elaborado por outro bibliotecário, Lopes de Quadros, o qual é bastante conciso e centrado na demanda de fundos para melhorar os serviços prestados pela biblioteca (QUADROS, 1898). 
assumiu a direção da biblioteca em fevereiro de $1900 .{ }^{34}$ Octaviano Ferreira (1870-1954) $)^{35}$ estava longe de possuir o lastro intelectual de Ismael Gracias, mas uma sólida formação acadêmica adquirida na Universidade de Bombaim facilitaria a sua nomeação para vários cargos públicos. Como já assinalamos, o seu consulado inauguraria a profissionalização do cargo, reforçada em 1901 com a sua transformação em cargo vitalício. ${ }^{36}$

Apesar de Octaviano Ferreira referir a existência de vários relatórios saídos das suas mãos, não consegui encontrar qualquer um. No entanto, podemos acompanhar os seus pontos de vista por duas das suas publicações, Horas vagas. Bibliotecas e Breves notas historicas sobre a Biblioteca Nacional de Nova-Goa; respectivamente dedicadas à história das bibliotecas e à biblioteca goesa.

A actividade desse bibliotecário, logo após assumir o cargo, reflete as suas ideias sobre a nova missão da Biblioteca de Nova Goa ao adquirir o estatuto de Biblioteca Nacional. As primeiras decisões tomadas por Octaviano Ferreira evidenciam que o novo diretor considerava que o Patrimônio Nacional que a biblioteca tinha o dever de reunir e preservar era o patrimônio intelectual goês. Nesse campo a reunião de um espólio o mais completo possível tornou-se um objetivo e, como explica, elegeria como prioridade construir uma coleção de bibliografia indo-portuguesa que acompanhasse passo a passo o movimento intelectual à época dessa terra e fornecesse aos vindouros e aos estrangeiros genuínos elementos para o inquérito e estudo do presente momento histórico. ${ }^{37}$

Para tal, Octaviano Ferreira tentou impor uma prática de Depósito Legal, ordenando aos editores e impressores goeses que remetessem as suas produções à biblioteca, ${ }^{38}$ e convenceu o governo do estado a isentar o porte postal de modo a facilitar o cumprimento da medida. ${ }^{39}$

34. "A Secção Indiana tem neste país, como é óbvio, uma importância particular (...) Claro que todo este imenso e luminoso movimento de investigações e de inquérito desperta o maior interesse nos estudiosos amantes da sua terra e torna-se, por isso, especialmente recomendável a aquisição de obras que versam este ramo de conhecimento" (FERREIRA, 1906, p. 38).

35.Sobre Octaviano Ferreira cf. COSTA ([s.d.], v. I, p. 403-404.

36. Regulamento de 19 de Julho de 1901 (Boletim official, n 68, 27 de agosto de 1901).

37.Idem, p. 14.

38. Boletim official, $\mathrm{n}^{\circ} 15,20$ de fevereiro de 1900.

39. Portaria $\mathrm{n}^{\circ}$ 65, 15 de março de 1900 (Idem, n 22, 20 de março de 1900). 
Complementarmente, convidaria os escritores goeses e seus descendentes a depositarem o conjunto da sua obra na biblioteca, de modo a que ela oferecesse os meios de estudo do percurso intelectual local:

A integridade desta bibliografia tinha ainda a importante vantagem de ser uma preciosa fonte de estudo para se proceder à comparação crítica entre o momento histórico passado e o presente, para se fazer uma ideia cabal e documentada do valor intelectual da obra e da geração que nos precedeu, para o seu exame sob o ponto de vista da evolução, da influência exercida nos escritores seguintes e, em fim, da correlação entre o movimento literário de ontem e de hoje.(FERREIRA, 1906, p. 16)

Indo mais longe, Octaviano Ferreira convidaria os escritores goeses e seus descendentes a depositarem os espólios manuscritos de modo a permitir uma reconstrução arqueológica da produção escrita goesa:

Convidei, em suma, a enviar todos os apontamentos biográficos ou autobiográficos acompanhados de retratos, autógrafos, planos de leitura porventura não levados a cabo e indicações de processos de escrita e da maneira de produzir do mesmo escritor, na convicção de que organizava, desta forma, subsídios abundantes para a compreensão cabal duma obra, a qual se não faz sem a história do espírito que a produziu. (Idem, p. 16-17) ${ }^{40}$

Finalmente, noticiando o investimento no concani nos meios literários goeses, sinal claro dum nascente nacionalismo cultural, Octaviano Ferreira assumiu a obrigação de reunir um fundo na língua vernácula, considerando que seria "indecoroso que na Biblioteca Nacional não encontrassem os estudiosos documentos necessários para ajuizarem do movimento literário do Konkani” (FERREIRA, 1906, p. 35).

Antes dele, Ismael Gracias já tinha vagamente tocado o problema, ao apelar aos escritores e impressores estabelecidos em Puna e em Bombaim que oferecessem à biblioteca os periódicos que publicavam em concani:

40.Nessas passagens o autor, formado em Letras, revelava uma profunda sensibilidade à genealogia da criação literária e à dinâmica entre criação e sociedade, que ainda hoje se mantém pertinente no campo dos estudos textuais. 
[...] para ficarem arquivadas neste instituto tão valiosas manifestações da literatura vernácula, como evidentes sinais da ressurreição duma língua, que é do trato usual em Goa e nas camadas menos esclarecidas da comunidade portuguesa [...] língua que, por muito tempo desprezada e perseguida, tem produzido ultimamente seus escritores, filólogos e lexicógrafos, não só entre os filhos do Konan, mas até entre os estrangeiros. (GRACIAS, 1893, p. 12)

A conjugação dos esforços desses dirigentes permitiria que em 1905 a biblioteca já possuísse um núcleo suficientemente significativo de obras editadas na Índia e a ela referentes para justificar a publicação de um repertório dedicado à temática. Da iniciativa do conservador de impressos e manuscritos, José Maria Barros de Valadares, esse levantamento continha 274 entradas para impressos e 38 para manuscritos, para além dum apenso intitulado "Subsídios para a história do jornalismo na Índia portuguesa", inventariando 91 jornais e revistas. Evidenciando que existia um público direcionado para a consulta dessas obras, Valadares explicava o seu intuito de facilitar o trabalho dos investigadores "que se dedicam a estudos orientalistas" (VALLADARES, 1905, p. V).

$\mathrm{Na}$ introdução ao Repertório, Valadares fazia um breve apanhado da literatura clássica indiana e uma exposição sobre o valor da língua sânscrita, com a assumida intenção de criticar o abandono que a Índia portuguesa votava a essa língua "que hoje é estudada entre as línguas clássicas nas universidades da Índia britânica e em quase todas as universidades europeias estrangeiras, e em Lisboa no curso superior de letras". " $\mathrm{Na}$ sequência dessa observação, o conservador introduzia a problemática da localização da identidade cultural goesa, apontando a necessidade de os goeses se reaproximarem das suas raízes: "A literatura da Índia é a que está ao alcance da nossa mão e do nosso país, original e única entre todas as outras; é a que pode ser estudada de perto e com mais proveito do que outras que não podem ser senão meras representações para o nosso espírito". ${ }^{42}$

Um breve escrutínio do repertório evidencia que as ambições dos seus sucessivos diretores no que respeitava à formação de uma vasta coleção de

41.Idem, p. X.

42.Idem, ibidem. 
literatura goesa/indiana estava ainda longe de se cumprir, particularmente no que concerne à ambição de Octaviano Ferreira envolver os intelectuais goeses na criação duma coleção de manuscritos visando possíveis abordagens acadêmicas da literatura goesa.

Às prioridades anteriormente referidas juntavam os diretores da Biblioteca Pública o cuidado de atualizá-la à produção portuguesa, em particular no que respeitava à literatura e às ciências sociais e humanas. Particularmente preocupado com a educação da mocidade, que afirmava ser o principal público da biblioteca, Ismael Gracias insistia na necessidade de dar-lhes instrumentos para melhorar o português, língua privilegiada de expressão da sua atividade intelectual, pelo exemplo dos expoentes da literatura portuguesa (GRACIAS, 1893, p. 8). ${ }^{43}$ Já Octaviano Ferreira, considerando que o núcleo dedicado à literatura portuguesa era parco e desordenado, apostava na oferta de um panorama da produção intelectual portuguesa nas suas diversas escolas e correntes (FERREIRA, 1906, p. 21-23).

Esse esforço de actualização estendia-se ainda à produção literária e científica europeia, sendo dada uma particular atenção aos modernos autores ingleses, franceses e alemães.

Finalmente, devido aos esforços desenvolvidos pelos bibliotecários, o espólio seria significativamente reforçado por via de ofertas. E nesse campo as redes de contatos podiam determinar a criação de áreas de interesse. Tal seria o caso de Joaquim dos Remédios Monteiro, ${ }^{44}$ um acadêmico descendente de goeses, radicado no Brasil. Por via da sua amizade com Ismael Gracias, durante os anos em que esteve à frente dos destinos da biblioteca, ofereceria um significativo conjunto de obras literárias brasileiras. Ismael Gracias destacaria nos seus relatórios a importância da constituição desse núcleo, sublinhando "os frisantes pontos de contatos étnicos e sociológicos, a pronunciada comunidade de aptidões e sentimentos, o mesmo dinamismo psíquico que apresentam os indianos e brasileiros" (GRACIAS, 1893, p. 9). ${ }^{45}$

43. "O português - diz muito acertadamente um nosso exímio escritor - podia ser a língua universal, porque tem a expressão para todas as ideias e para todos os sentimentos, tintas para todas as matizes” (GRACIAS, 1895, p. 12).

44. Sobre Remédios Monteiro v. COSTA ([s.d.], v. II, p. 321-325).

45. Estamos convencidos de que existe um filão a explorar na área da história das relações culturais entre Goa e o Brasil. O estabelecimento, temporário ou definitivo, de alguns membros das elites ca- 


\section{Conclusão}

Entre 1892 e 1906, datas que balizam os relatórios e folhetos que abordamos neste texto, a Biblioteca Pública de Goa mudaria a sua face, atualizandose ao movimento de expansão intelectual da sociedade em que se inseria, e aspirando a dinamizar o seu desenvolvimento. Se considerarmos que o seu público, de acordo com o descrito nos regulamentos e relatórios referidos, era principalmente constituído por estudantes, acadêmicos e investigadores e funcionários públicos, é de presumir que essa evolução tenha tido um impacto direto na formação intelectual das elites goesas, sendo por isso relevante o seu estudo. O catálogo da biblioteca, publicado por Octaviano Ferreira em 1907 e sucessivamente corrigido e atualizado até $1912,{ }^{46}$ traduz os frutos desse investimento, espelha uma concepção de cultura e também fala pelos seus silêncios. ${ }^{47}$

A relevância conferida pelos seus diretores às matérias indianas deve ser lida como sintoma do despertar de uma nova sensibilidade à realidade local e aos problemas identitários. No entanto, não deve levar-nos a concluir que as suas políticas subvertiam a hegemonia da cultura europeia em geral, e portuguesa em particular, na contribuição dada pela biblioteca à formação de uma visão goesa do mundo. A verdade é que o catálogo da biblioteca era dominado pela literatura e produção científica ocidental, mesmo no que respeitava à leitura da realidade indiana.

tólicas goesas no Brasil nos últimos séculos, sem que perdessem a ligação à terra natal, poderá ajudar a explicar, por exemplo, a significativa presença de autores brasileiros coevos nas páginas da imprensa periódica goesa como nos evidencia Helder Garmes (GARMES, 2004). Terá sido Remédios Monteiro, recomendado por Ismael Gracias o prefaciador de Dulce e Jacob, a fazer chegar a obra à apreciação do Visconde de Taunay. A apreciação que o próprio GIP publicaria e comentaria em O Ultramar, revela o atualizado conhecimento que o intelectual brasileiro tinha da realidade cultural e política goesa $(O$ Ultramar, 20.11.1897, 27.11.1897, 4.12.1897, 11.12.1897; como se sabe a carta de Taunay seria sucessivamente publicada nas edições posteriores a essa data).

46. Catálogo... (1907, 1909); Biblioteca... (1910, 1911, 1912).

47.Em 1912, o jornal Prabhat lamentava as imensas lacunas existentes no que respeitava às obras em língua marata, a principal língua de comunicação literária e política da população hindu (PINTO, 2007, $110,119)$. 


\section{Referências Bibliográficas}

\section{Fontes:}

Bibliotheca Nacional de Nova Goa. Anno de 1910. Obras entradas. 9 p. Bibliotheca Nacional de Nova Goa. Anno de 1911. Obras entradas. 15 p. Bibliotheca Nacional de Nova Goa. Anno de 1912. Obras entradas. 11 p. Boletim Official Governo Geral do Estado da Índia, 1889-1906, em especial os artigos, estatísticas e regulamentos citados: n. 34 (28 Março 1889), n. 83 (28 Julho 1892) n. 109 (8 Março 1895), n. 109 (8 Outubro1895), n. 134 (5 Dezembro1895), n. 15 (20 Fevereiro1900), n. 22 (20 Março 1900), n. 28 (10 Abril 1900), n. 68 (27 Agosto 1901)

Catalogo dos livros, opusculos e manuscritos pertencentes á Bibliotheca Nacional de Nova Goa (India Portugueza). Nova Goa: Imprensa Nacional, 1907.360 p

Catalogo dos livros, opusculos e manuscritos pertencentes á Bibliotheca Nacional de Nova Goa (India Portugueza). Serie 2 ${ }^{a}$. Nova Goa, Imprensa Nacional, 1909. 104 p.

FERREIRA, Octaviano Guilherme. Horas vagas. Bibliotecas. Nova Goa: Tyipographia da "Casa Luso Francesa", 1905. 26 p.

. Breves notas historicas sobre a Biblioteca Nacional de Nova-Goa. Nova Goa: Typographia da Minerva Indiana, 1906. 56 p.

GRACIAS, José António Ismael. Biblioteca publica de Nova Goa. Relatorio do Bibliothecario-Director. In: Supplemento ao numero 123 do Boletim Official do Governo Geral do Estado da India, 29 October 1892.

. Biblioteca publica de Nova Goa. Relatorio do anno económico de 1892 a 1893. Nova

Goa: Imprensa Nacional, 1893. 43 p.

. Biblioteca publica de Nova Goa. Relatorio do anno económico de 1893 a 1894. Nova

Goa: Imprensa Nacional, 1894. 52 p.

. Biblioteca publica de Nova Goa. Relatorio do anno económico de 1894 a 1895. Nova

Goa: Imprensa Nacional, 1895. 44 p.

. O "Instituto Vasco da Gama". In: O Oriente Português, v. 6, n 5-6, 1909, p. 129-139

QUADROS, Manuel Lopes de. Relatorio acerca da Biblioteca Nacional de Goa relativo a 1897. Nova Goa: Imprensa Nacional, 1898. 14 p.

Ultramar, 20.11.1897, 27.11.1897, 4.12.1897, 11.12.1897

VALLADARES. Repertorio bibliographico das obras que tratam da India e possue a Bibliotheca Nacional de Nova Goa. Nova Goa: Typographia da "Casa Luso Francesa", 1905. 37 p.

\section{Estudos:}

COSTA, Aleixo Manuel da. Dicionário de literatura goesa. Lisboa: Instituto Cultural de Macau: Fundação Oriente, [s.d.]. 3 v. 
DOMINGOS, Maria Manuela Delgado. Biblioteca Nacional: crónica de 200 anos. Lisboa: Inapa, 1992. 27 p. . Materiais para a história da Biblioteca Nacional. Lisboa: M.D. Domingos, 1994. $78 \mathrm{p}$.

GARMES, Hélder. Origem e estabelecimento da imprensa e da literatura em Goa. In: Oriente: engenho e arte. São Paulo: Alameda, 2004. p. 15-85.

GOULEMOT, Jean-Marie. Bibliothèques, encyclopédisme et angoisses de la aperte: l'exhaustivité ambighë des Lumières. In: BARATIN, Marc; JACOB, Christian (Dir.). Le pouvoir des bibliothèques: le mémoire des livres en Occident. Paris: Albin Michel, 1906. p. 285-298.

HARRIS, Michel H. History of libraries in the western world. $4^{\text {th }}$ ed. Md. \& London: Scarecrow Press, 1995. 301 p.

JACOB, Christian. Préface. In: BARATIN, Marc; JACOB, Christian (Dir.). Le pouvoir des bibliothèques: le mémoire des liures en Occident. Paris: Albin Michel, 1996. p. 11-19

PEREIRA, Gabriel. Biblioteca Nacional de Lisboa. Lisboa: Typographia do Dia, 1898. $14 \mathrm{p}$.

PINTO, Rochelle. Between empires. Print and politics in Goa. Delhi: Oxford University Press, 2007. XIV. 299 p.

PRATES, Maria Cristina Costa Simões. Biblioteca Nacional: evolução de um conceito. In: Revista da Biblioteca Nacional, s. 2, v. 1, n. 1-2, p. 251-264,jan./dez. 1986.

PROENÇA, Raul. A Biblioteca Nacional: breves noções históricas e descritivas. In: Publicações da Biblioteca Nacional. Volume 1 (único). Lisboa: Livraria Universal, p. 7-57.

RODRIGUES, Pia de Menezes. Central library, Panaji, Goa (brief sketch with special reference to local history Collection). In: GUPTA, B. M.; JAIN, V. K. (Eds.). Handbook of libraries, archives and information centres in India. v. 8. Delhi: Aditya Prakashan, 1990. p. 199-209

. Emergence of a Goan elite of intellectuals (1820-1926). In: BORGES, Char-

les J.; PEREIRA, Óscar G.; STUBE, Hannes (Eds.). Goa and Portugal: History and Development. Delhi: Concept Publishing Company, 2000. p. 197-215

SAID, Edward W. Orientalism. London: Penguin Books. XXXIII, 2003. 396 p.

TEIXEIRA, Maria Isabel Gracias de Fontoura de Sousa; DIAS, Paulo Colaço. José António Ismael Gracias (1857-1919). Disponível em: <www.supergoa.com/pt/read/ news_cronica.asp?c_news=693>. Acesso em: 23/02/2011.

Recebido em 08/03/2011 e aprovado em 09/04/2011. 